\title{
Characterize Plug-In Electric Vehicle Driver Away-From-Home Parking Behavior in The EV Project
}

Idaho National Laboratory

September 2015

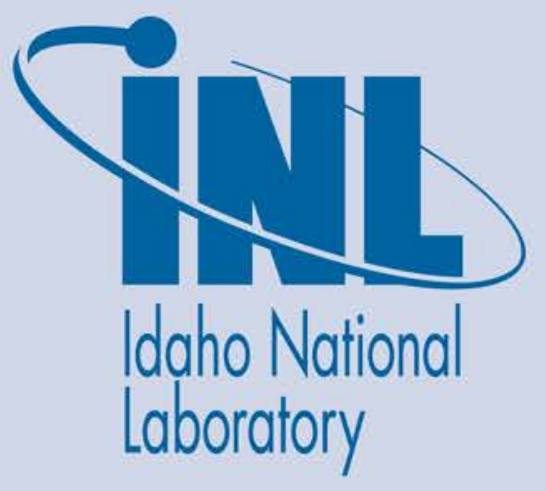

The INL is a U.S. Department of Energy National Laboratory operated by Battelle Energy Alliance 
INL/EXT-15-36323

\section{Characterize Plug-In Electric Vehicle Driver Away-From-Home Parking Behavior in The EV Project}

Idaho National Laboratory

September 2015

Idaho National Laboratory
Idaho Falls, Idaho 83415

http://www.inl.gov 


\section{Characterize Plug-In Electric Vehicle Driver Away-From-Home Parking Behavior in The EV Project}

September 2015

\section{Key Conclusions}

- In the San Diego region, 789 Leaf and Volt plug-in electric vehicles (PEVs), providing location data in the last half of 2013, parked away from home 232,083 times in 21,636 distinct locations.

- $7 \%$ of all away-from-home parking events included vehicle charging.

- $55 \%$ of the distinct parking locations were only frequented by a single PEV.

- Retail locations at shopping malls in San Diego saw the largest number of distinct vehicles parking during the last half of 2013.

- $26 \%$ of PEV drivers participating in The EV Project parked away from home less than once a day.

- $32 \%$ of the PEV drivers participating in The EV Project never charged away-from-home during the last half of 2013.

- PEV drivers participating in The EV Project charged away from home 16,557 times in 868 unique charging locations during the last half of 2013 , with $81 \%$ of those locations averaging less than one charge per week.

- The most highly utilized away-from-home charging locations in the San Diego region are at workplace/business office locations.

\section{Introduction}

The EV Project deployed over 5,000 alternating current Level 2 charging stations and over 100 dual-port direct current fast chargers for commercial use in 17 geographic regions across the United States. Approximately 8,300 Nissan Leaf ${ }^{\mathrm{TM}}$ and Chevrolet Volt PEVs participated in The EV Project by allowing data to be collected, characterizing operation of their PEVs and their charging usage. In the San Diego region, final PEV enrollment included 681 Leafs and 272 Volt owners.

The PEV charging stations deployed as part of The EV Project included both residential and non-residential sites.
Non-residential sites included electric vehicle supply equipment (EVSE) installed in workplace environments, fleet applications, and those that were publicly accessible near retail centers, parking lots, and similar locations. The EV Project utilized its Micro-Climate ${ }^{\circledR}$ planning process to determine potential sites for publicly accessible EVSE in San Diego. This process worked with local stakeholders to target EVSE deployment near areas where The EV Project residential participants resided and where significant PEV traffic was expected. Using this process, The EV Project installed 545 non-residential fleet, workplace, and publicly accessible EVSE at 164 locations in the San Diego region.

Another report titled, "Do Plug-In Electric Vehicle Drivers Park near Publicly Accessible Electric Vehicle Supply Equipment in San Diego but Not Use Them?", ${ }^{1}$ investigated the San Diego PEV drivers' use of 139 of these publicly accessible EVSE locations. It examined how frequently drivers parked near publicly accessible EVSE locations, but did not use them for charging. It concluded that parking near EVSE installed by The EV Project accounted for 3\% of vehicle away-from-home parking. However, this report looks in greater detail at the PEV parking locations in San Diego to determine if there are highly utilized parking locations that should have EVSE available.

\section{Analysis Approach}

Participants in The EV Project gave written consent for researchers to collect and analyze data from their PEVs and from the EVSE they used. In the last half of 2013, 467 Leafs and 322 Volts provided vehicle parking and charging information when away from home. The number of Volts exceeded the final enrollment in the San Diego region (i.e., 272) because some Volts enrolled in other regions visited the San Diego region and parked or charged there.

Data for PEV parking away from home was analyzed to identify the number of distinct parking locations. These parking locations were investigated to identify common characteristics and develop insight into PEV parking behavior. Parking data were also used to identify the number of times PEVs parked away from home. The data set also included charge information when the vehicle was away from home, allowing a determination of when and where PEVs charged. Vehicle data were separately provided by Nissan Leafs and Chevrolet Volts, allowing results to be analyzed by vehicle type. Venue and sub-venue classifications were identified for parking and charging locations using global positioning system (GPS) coordinates from the data set, as well as Google Earth Pro and Google Maps information. 
In The EV Project, it was originally assumed that publicly accessible EVSE would have a 1/4-mile radius of influence, meaning a person would likely walk up to one-fourth a mile from the EVSE where his/her vehicle is charging to a desired destination. However, actual practice suggests that this distance is too far and a more realistic sphere of influence is about $300 \mathrm{ft}$ (i.e., the length of a football field). This 300-ft sphere of influence was used for the analyses described herein.

The period from July 1 to December 31, 2013, was chosen for analysis because the vehicle enrollment in The EV Project was complete and PEV driver habits were well established. In addition, the non-residential EVSE infrastructure was essentially fully deployed; therefore, PEV drivers would be aware of the EVSE locations.

\section{Data Analyzed Results}

\section{Residential Participants}

The San Diego region of The EV Project encompassed most of San Diego County, with project participants enrolled from all areas of the region. Figure 1 shows the rather homogeneous distribution of the home location for project participants. The size of the region can be characterized by the distance from the northernmost areas in Oceanside to the southern areas of Imperial Beach, which is a distance of about 50 miles. While all areas would be within the range of a Volt using both the charge depleting and charge sustaining modes, the typical range of the Leaf could likely allow it to complete all but the longest round trips in the area. Thus, away-from-home charging may not be a necessity in all situations, but more of a convenience for range extension to include other trip stops, or increase Volt operation in charge depleting mode.

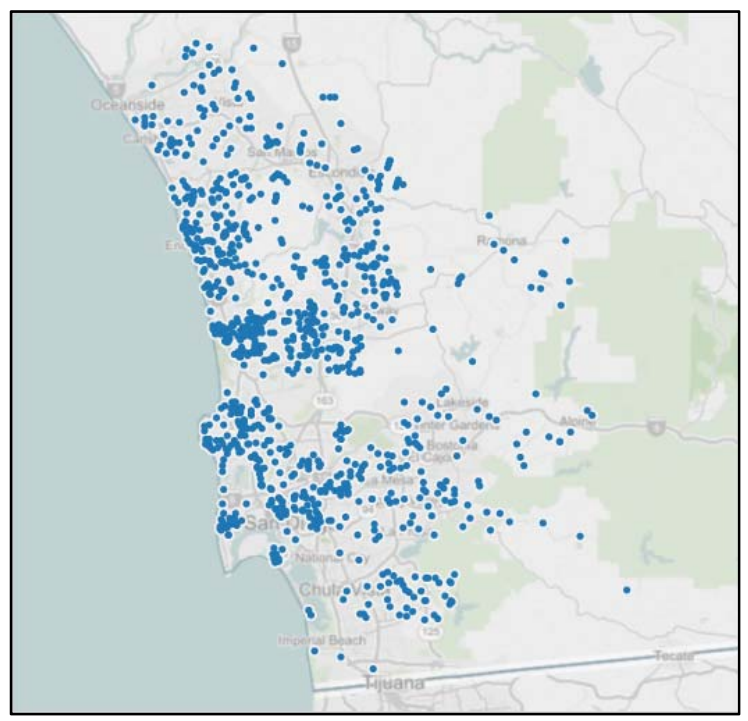

Figure 1. Home location for San Diego participants in The EV Project.

\section{Highly Frequented Sites}

Figure 2 displays away-from-home parking locations for the second half of 2013 for Volts and Leafs enrolled in The EV Project. Volt trip end points are colored red and Leaf trip end points are colored blue. As one would expect, there is significant overlap in the parking locations. A summary of the data set is shown in Table 1.

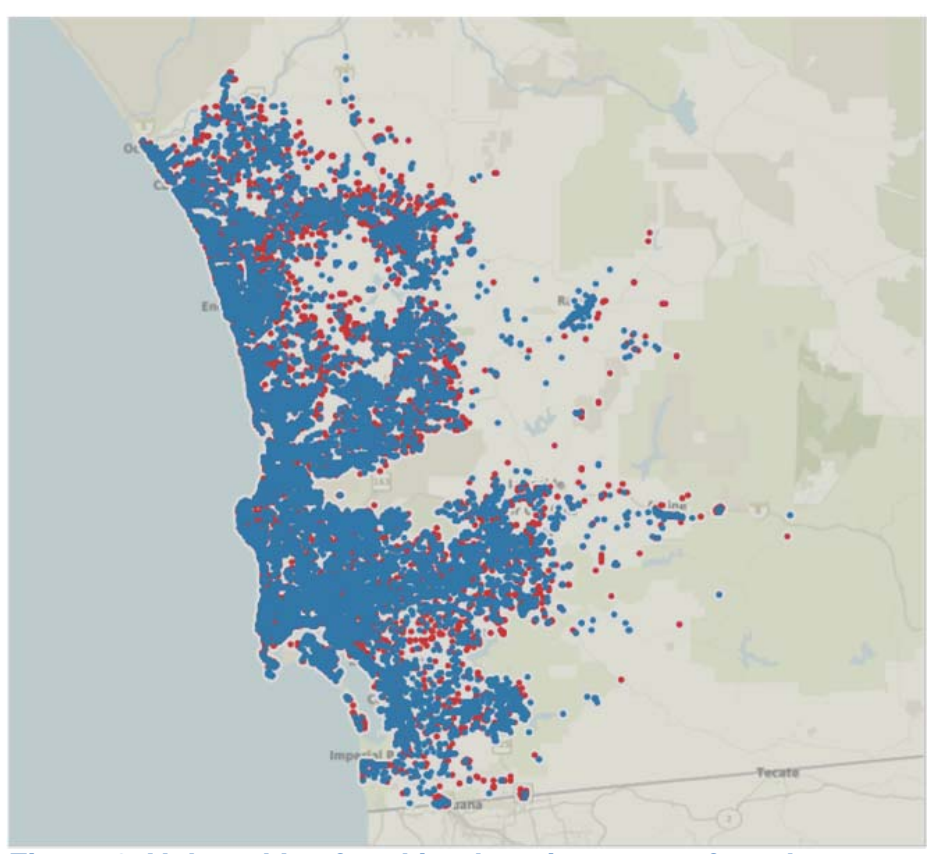

Figure 2. Volt and Leaf parking locations away-from-home.

Table 1. PEV away-from-home parking.

\begin{tabular}{cccc} 
Vehicle & $\begin{array}{c}\text { Charged } \\
\text { Away From } \\
\text { Home }\end{array}$ & $\begin{array}{c}\text { Parked } \\
\text { Away From } \\
\text { Home }\end{array}$ & $\begin{array}{c}\text { Percent of } \\
\text { Charge } \\
\text { Events }\end{array}$ \\
\hline Leaf & 8,736 & 124,150 & $7 \%$ \\
Volt & 7,821 & 107,933 & $7 \%$ \\
Total & 16,557 & 232,083 & $7 \%$ \\
\hline
\end{tabular}

There were a total of 232,083 parking events at 21,636 distinct sites. As noted above, distinct sites are defined in zones with a $300-\mathrm{ft}$ radius. The most frequently visited site had a total of 467 visits by 31 different vehicles. However, there were many sites with high parking events, but a low number of different vehicles. This was the case for workplace parking. A single vehicle could also make many trips to a single spot over the course of the 6-month duration of the data set (e.g., favorite restaurant, grocery store, girlfriend, etc.).

Sites that had a high numbers of parking events but few different vehicles were of less interest in understanding the overall away-from-home parking behavior of PEV drivers, because they identify the driving behavior for select individuals. For example, there were 11,939 sites (55\% of 
all sites) where only a single vehicle parked during the evaluation period. These single PEV parking locations also accounted for $21 \%$ of all parking events. Figure 3 displays the cumulative percent of parking events related to the number of different vehicles.

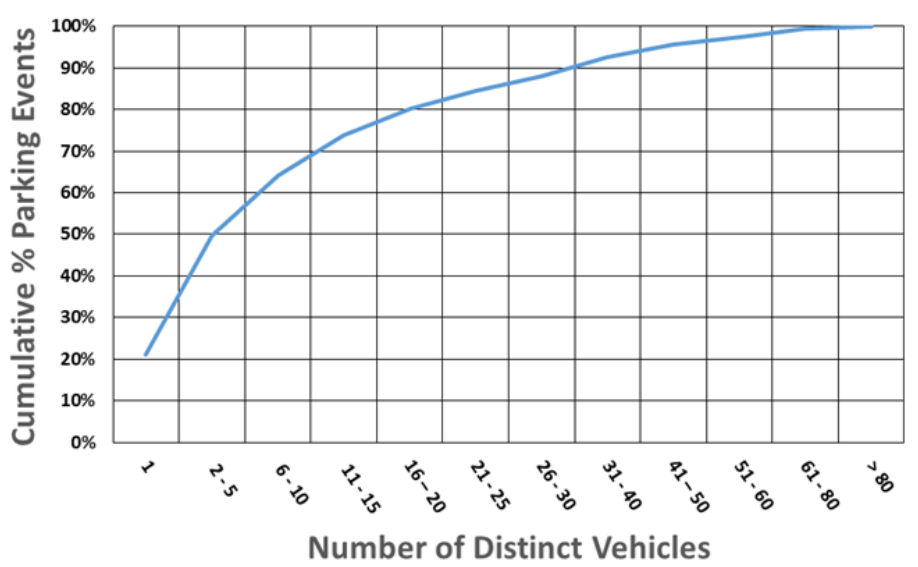

Figure 3. Cumulative percent of different vehicles per site.

Likewise, sites that attracted high numbers of different vehicles but provided low numbers of parking events are of less interest in characterizing the larger group of drivers. For example, 28 distinct vehicles visited one site that had a total of 30 parking events, meaning only 2 or 3 of those vehicles came back for a second visit. The site attracting the most distinct vehicles (i.e., 105) had 241 parking events. Figure 4 displays the cumulative percent of parking events based on the number of parking events per site.

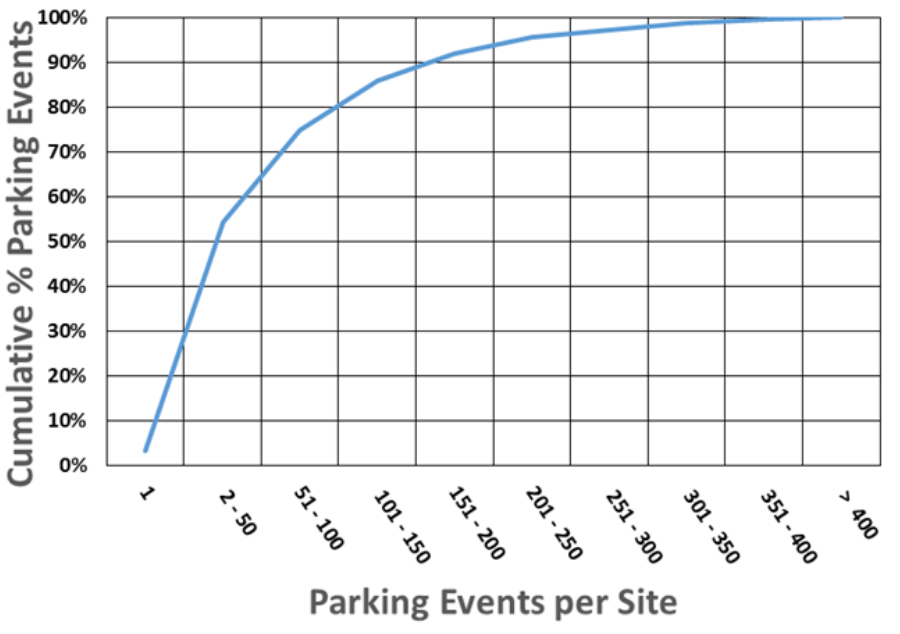

Figure 4. Cumulative percent of parking events per site.

With 26 weeks in the study period, 52 parking events per site is an average of two visits per week. Further, $55 \%$ of all parking events were at sites that averaged two or fewer visits per week.
Figure 5 illustrates the relationship between parking events and the number of different vehicles.

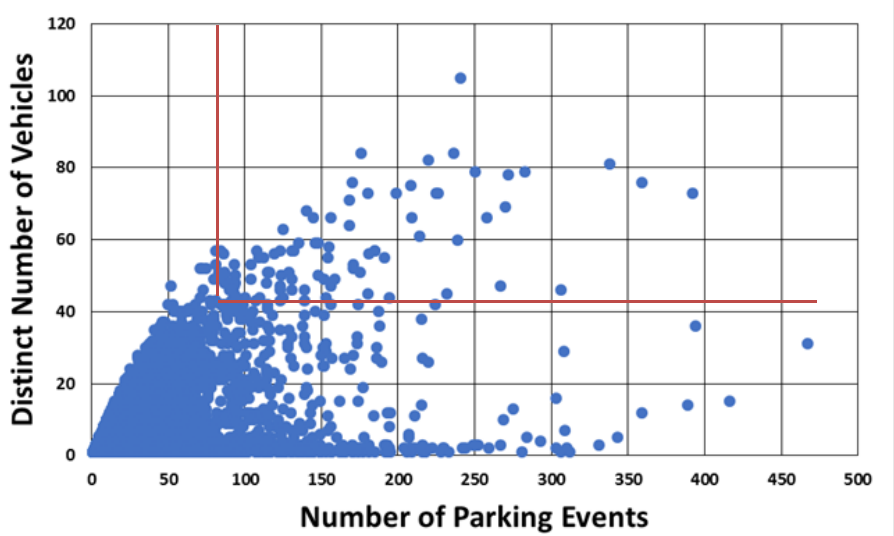

Figure 5. Different vehicles versus number of parking events.

Of greater interest are sites with high numbers of parking events and high numbers of different vehicles. Data were provided from 789 vehicles (467 Leafs and 322 Volts) in the 6-month analysis period. The most attractive site for vehicles saw 105 of these vehicles (i.e., 13\%) park there. Sites that attracted at least $40 \%$ of these vehicles (i.e., 42 vehicles) and at least double that number of parking events (i.e., 84 events) were investigated further. There were 100 of these sites and they are represented by those to the right and above the red lines of Figure 5. Figure 6 shows the geographic location of these 100 parking locations in red.

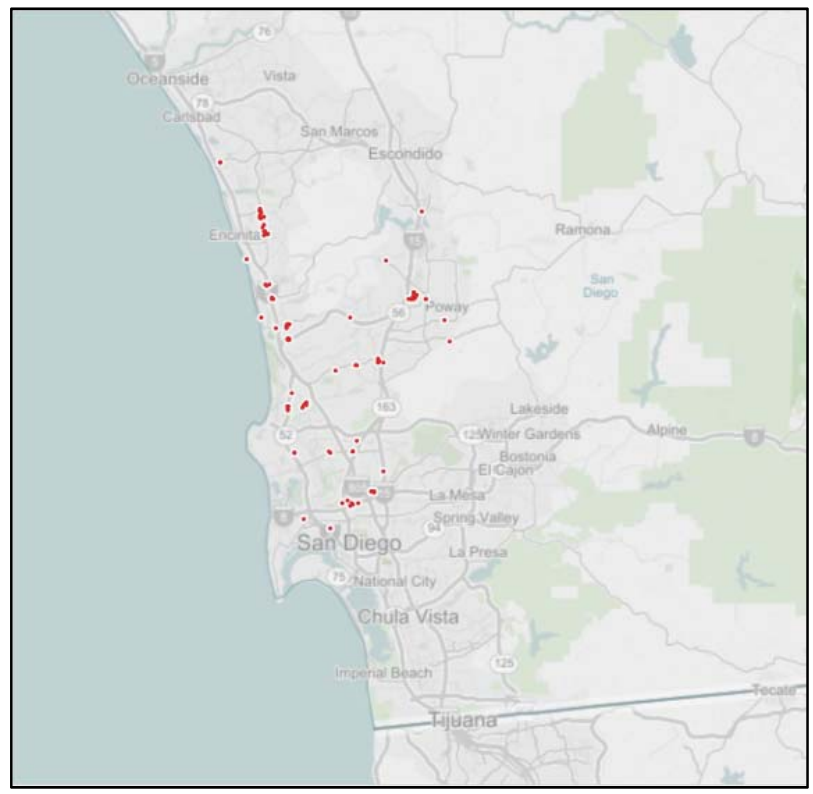

Figure 6. Top 100 parking sites.

These 100 sites represent less than $1 \%$ of the parking sites, but they provide 15,646 (i.e., $6.7 \%$ ) of the parking events, with an average of 56 distinct vehicles per site. 
Figure 6 shows that many of these sites are in clusters. Because they represent points with 300-ft buffers, a popular venue location may contain several distinct parking sites. One example is shown in Figure 7.

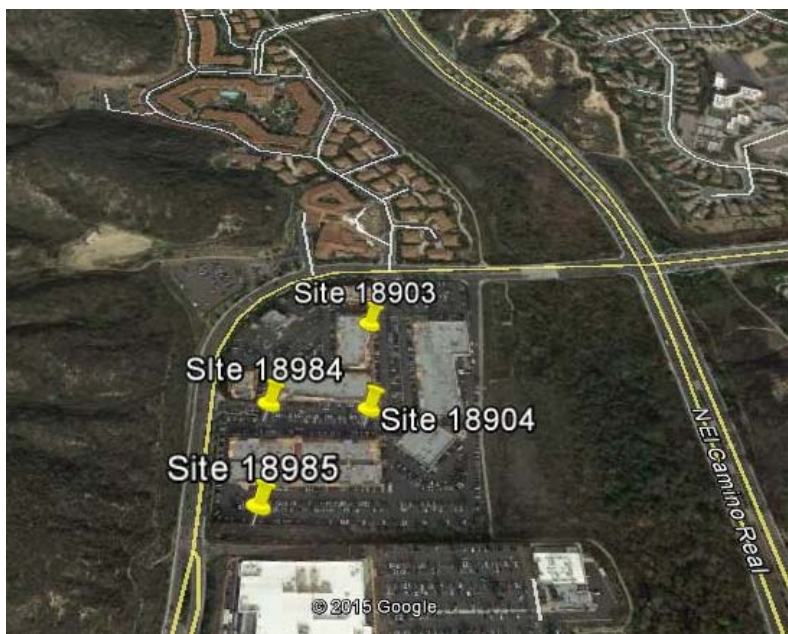

Figure 1. Cluster of highly utilized sites (Google Earth).

Table 2 identifies the venue and sub-venue of these 100 locations using the definitions presented in Reference 2.

Table 2. Venue of top 100 most frequented parking locations.

\begin{tabular}{cccc} 
Venue & Sub-Venue & $\begin{array}{c}\text { Number } \\
\text { Sites }\end{array}$ & $\begin{array}{c}\text { Distinct } \\
\text { Venues }\end{array}$ \\
\hline Retail & Mall/Shopping Center & 68 & 28 \\
Retail & Retail - Big & 25 & 16 \\
Retail & Retail - Small & 1 & 1 \\
Retail & Auto Dealer & 3 & 2 \\
Leisure & Ocean Attraction & 2 & 2 \\
Medical & Medical & 1 & 1 \\
\hline
\end{tabular}

The most frequently visited locations by the highest number of distinct vehicles are retail locations with shopping malls followed by big retail locations. The most frequented mall/shopping centers included the following:

- Del Mar Highlands Town Center

- Carmel Mountain Plaza

- La Jolla Town Center.

Most popular retail locations included the following:

- Costco

- Home Depot

- Ikea.

\section{Vehicle Trips}

The number of times a particular reporting vehicle parked away from home during the period was investigated.
Figure 8 shows the percentage of vehicles versus the average number of times it parked away from home per week.

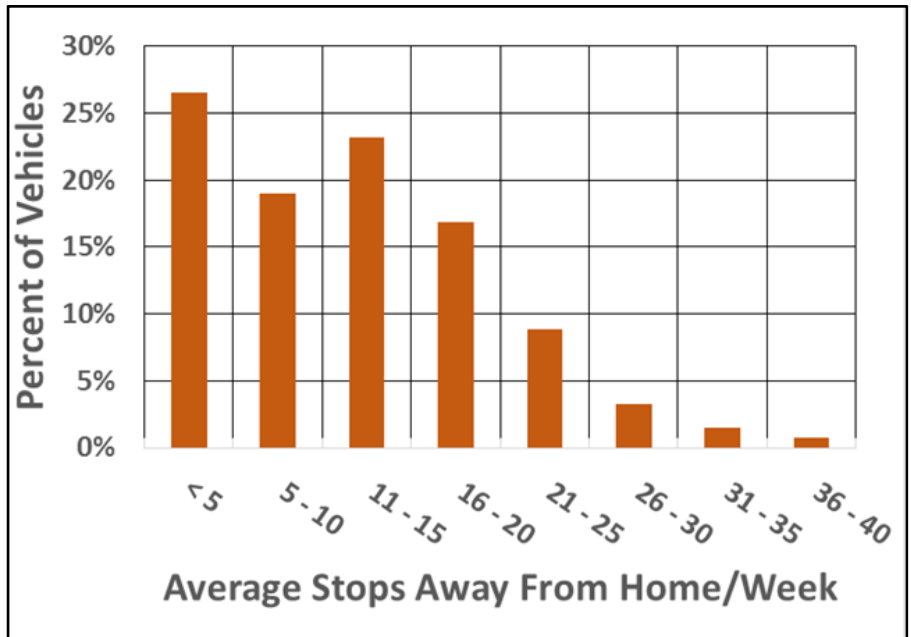

Figure 8. Average stops away from home per week.

Significantly, $26 \%$ of PEV drivers parked away from home less than once a day during the analysis period. It is likely that some of these are the Volts visiting from other regions, but, at most, these would be $6 \%$ of all PEVs. Conversely, one vehicle parked in locations away from home an average of nearly 39 times per week.

The National Household Travel Survey provides information to assist transportation planners and policy makers on travel and transportation patterns. The latest published survey is for the year 2009 and it reports an average of 3.02 trips per driver per day. ${ }^{3}$ A trip consists of a key-on and key-off event. Assuming the daily trips end at home (this location was not counted in the PEV data), the Travel Survey would report 2.02 trips (or trip end points) per day that were away from home, which would be 14.1 trip end points away from home weekly. On average, $64 \%$ of PEV drivers in The EV Project in the San Diego region took fewer trips per day than the national average.

\section{Away-From-Home Charging Analysis}

The data set included information related to the vehicle charging away from home. Figure 9 presents an overview of these data. For this analysis, the number of charge events away from home is compared to the number of parking events away from home to determine a percentage of charging events. Significantly, $78 \%$ of vehicles charge less than one out of 10 times they park away from home.

\section{No Away-From-Home Charging}

While all of the 789 vehicles recorded away-from-home parking events, 255 (i.e., 32\%) did not record any away-from-home charging events during this period. Table 3 provides a summary of those not charging away 
from home. The "Percent of Vehicle Make" column represents the fraction of Leafs and the fraction of Volts in the data set that did not charge away from home. The difference between PEV makes was not significant.

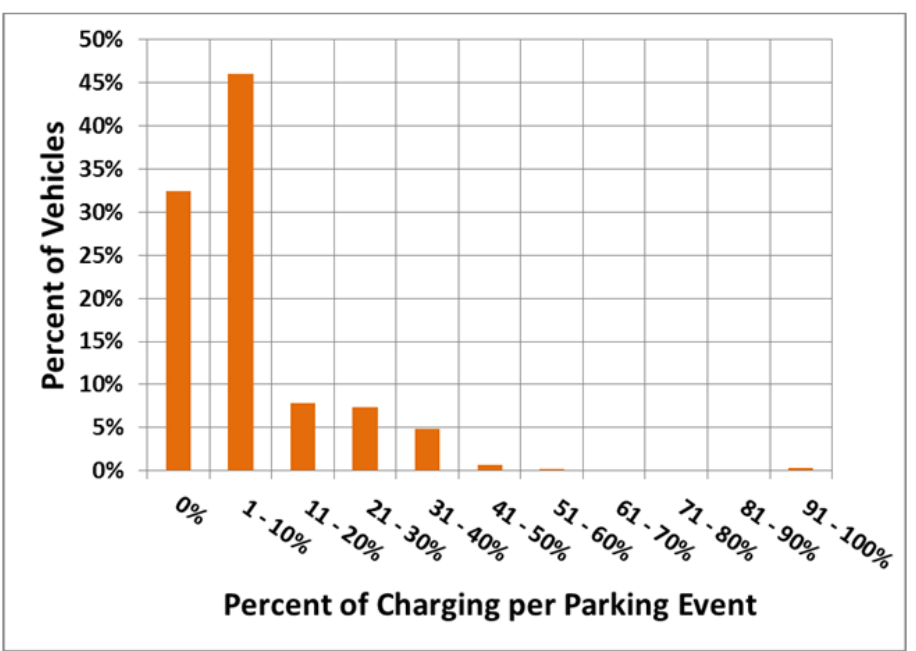

Figure 9. PEV charging overview.

Table 3. PEVs that did no charging away from home.

\begin{tabular}{cccc} 
Make & $\begin{array}{c}\text { Number of } \\
\text { Vehicles }\end{array}$ & $\begin{array}{c}\text { Parking } \\
\text { Events }\end{array}$ & $\begin{array}{c}\text { Percent of } \\
\text { Vehicle Make }\end{array}$ \\
\hline Leaf & 161 & 29,921 & $34 \%$ \\
Volt & 94 & 21,468 & $29 \%$ \\
Total & 255 & 51,389 & $32 \%$ \\
\hline
\end{tabular}

Information and attitudes of The EV Project participants concerning their experience with their PEVs was solicited using a survey in June 2013; the survey involved all regions of The EV Project. ${ }^{4}$ At that time, some had nearly 3 years of experience with their PEV. The respondents to the survey were segmented by their vehicle data so that when asked, "How often do you use public charging?" it could be compared to their actual vehicle data.

While $69 \%$ reported they have never or rarely use public charging, verifiable vehicle data showed that only $16 \%$ actually had no away-from-home charging. Thus, the $32 \%$ of vehicles identified in Table 3 is not surprising.

\section{Away-From-Home Charging}

Figure 10 shows the away-from-home charging locations where the size of the location represents the number of charge events by all vehicles at that location.

From the 16,557 individual away-from-home charge events in the data set, there are a total of 868 unique charging sites identified from vehicle data. Figure 11 provides information on how frequently the sites were utilized. Because there were 26 weeks in the data set, 25 charges per site would average less than one charge per week. Fully, $81 \%$ of the charge sites are in this category.

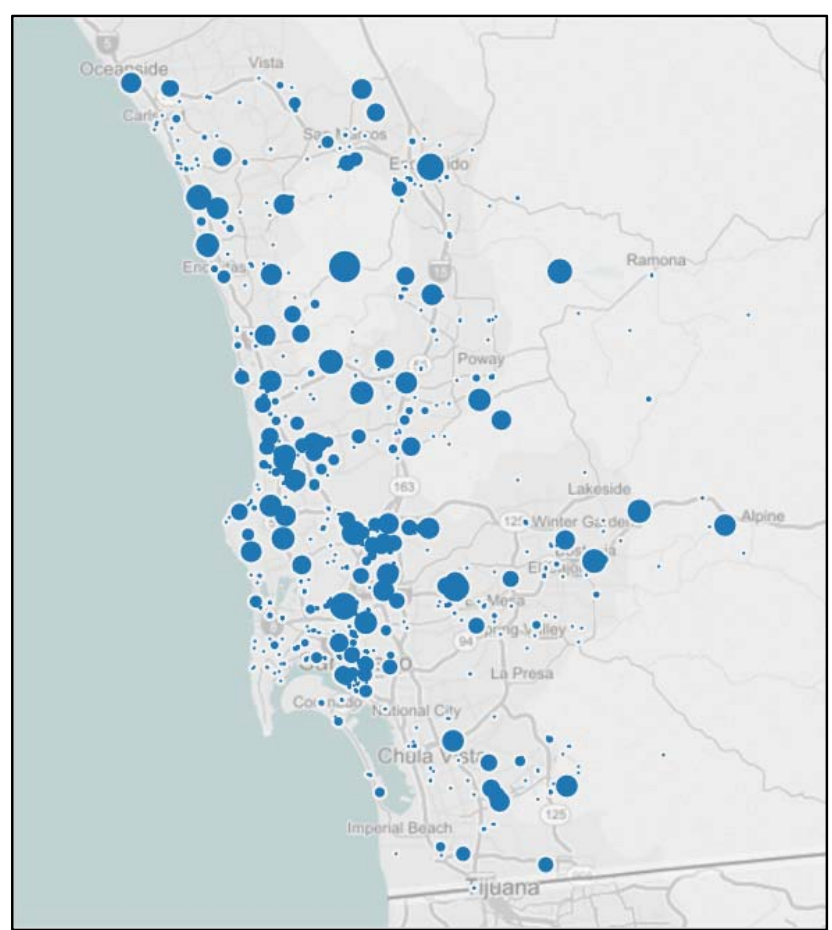

Figure 10. PEV away-from-home charging.

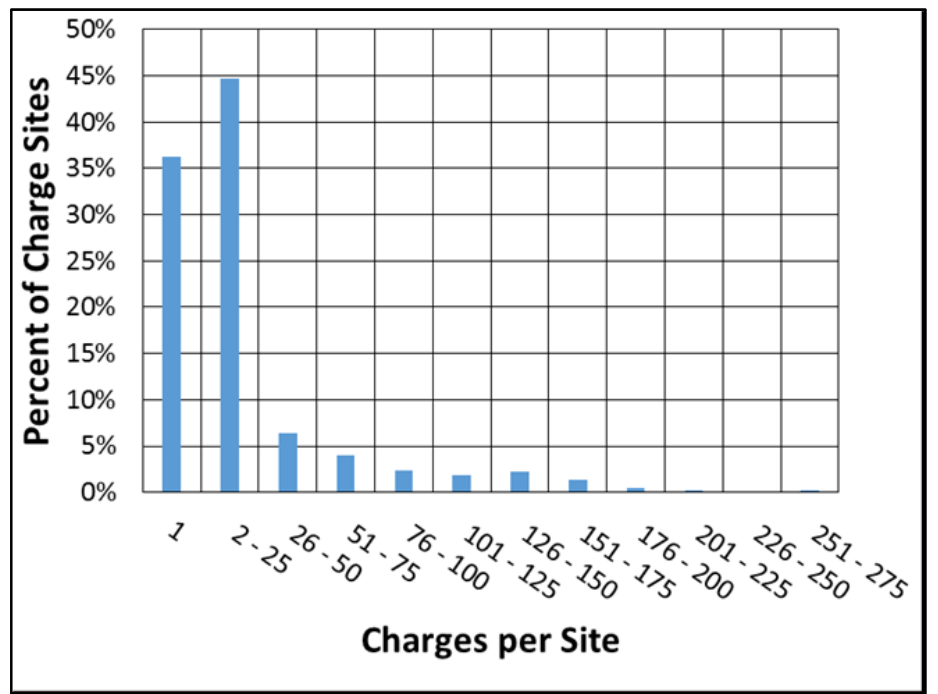

Figure 11. Distribution of charges per charge site.

The 75 most utilized sites for charging received 76 or more charges per site. This is an average of approximately 3 charges per week and accounts for $9 \%$ of the charging activity. These sites were investigated further.

Although the data set was derived from parking and charging sites that were away from the PEV drivers' residences, 43 of the highest utilized sites were located in residential areas, suggesting they were, in fact, home locations. The identification of whether a site is home or away-from-home depends on comparison of GPS coordinates entered in the database during EVSE 
installation and the GPS coordinates of the vehicle during a charge event. Errors in either can result in misidentification of the sites, which is likely the case for these 43 sites. Final determination is impossible without viewing the GPS locations in a mapping program, as was done for this report. The remaining highly utilized charging sites are reported in Table 4.

Table 4. Venue identification of highly utilized charging sites.

\begin{tabular}{cccc} 
Venue & Sub-Venue & $\begin{array}{c}\text { Number } \\
\text { of Sites }\end{array}$ & $\begin{array}{c}\text { Total Charge } \\
\text { Events }\end{array}$ \\
\hline Workplace & $\begin{array}{c}\text { Business } \\
\text { Office }\end{array}$ & 24 & 3,245 \\
Retail & $\begin{array}{c}\text { Mall/Shopping } \\
\text { Center }\end{array}$ & 2 & 250 \\
Retail & Retail - Big & 2 & 216 \\
Retail & Auto Dealer & 2 & 264 \\
Hotel & Hotel & 2 & 177 \\
\hline
\end{tabular}

Qualcomm provides a significant number of the workplace sites noted above. Non-residential EVSE installed by The EV Project are located in the vicinity of 14 of these 32 highly utilized charging locations.

As with parking events, the greatest interest lies in investigating the sites with high numbers of charging events and high numbers of different vehicles. Figure 12 illustrates this relationship.

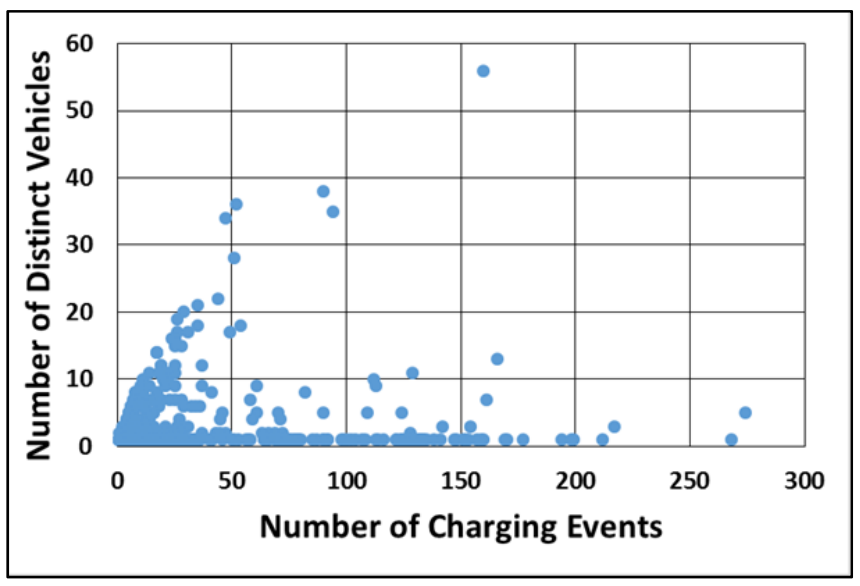

Figure 12. Different vehicles versus number of charging events.

Sites with greater than 10 different vehicles and 26 or more charging events (one per week average) over the 6-month analysis period were investigated further. There are 20 such sites.

It has been noted that all but three auto dealer sites and one big retail site were served by non-residential EVSE installed by The EV Project.
Table 5. Identification of venues with highly utilized charging sites and a high different vehicle count.

\begin{tabular}{|c|c|c|c|}
\hline Venue & Sub-Venue & $\begin{array}{l}\text { Number } \\
\text { of Sites }\end{array}$ & $\begin{array}{l}\text { Total Charge } \\
\text { Events }\end{array}$ \\
\hline Workplace & $\begin{array}{l}\text { Business } \\
\text { Office }\end{array}$ & 3 & 407 \\
\hline Retail & $\begin{array}{l}\text { Mall/Shopping } \\
\text { Center }\end{array}$ & 4 & 277 \\
\hline Retail & Auto Dealer & 3 & 157 \\
\hline Retail & Retail - Big & 2 & 144 \\
\hline Leisure & $\begin{array}{c}\text { Arts and } \\
\text { Entertainment }\end{array}$ & 3 & 125 \\
\hline Hotels & Hotels & 2 & 75 \\
\hline Parking Lot & $\begin{array}{c}\text { Parking } \\
\text { Lots/Garages }\end{array}$ & 1 & 49 \\
\hline Transportation & $\begin{array}{c}\text { Transportation } \\
\text { Hub }\end{array}$ & 1 & 35 \\
\hline Education & $\begin{array}{c}\text { Educational } \\
\text { Services }\end{array}$ & 1 & 26 \\
\hline
\end{tabular}

\section{Conclusions}

Participants in The EV Project came from all areas of the San Diego region. Because only $7 \%$ of all parking events away from home involved charging, the 789 PEVs reporting data in the last half of 2013 likely did not charge their vehicle away from home for range extension, but may have charged for convenience. The most frequently used location for away-from-home charging is the PEV driver's workplace. The most frequently visited locations by different vehicles are shopping malls and "big box store" retail locations.

Where PEV drivers park away from home is as diverse as the individual. Where they charge is also very individualized and primarily focused on their workplace. Retail locations, especially malls and shopping centers, provide the most attractive sites for large numbers of different PEVs.

\section{About The EV Project}

The EV Project was the largest PEV infrastructure demonstration project in the world, equally funded by the United States Department of Energy (DOE) through the American Recovery and Reinvestment Act and private sector partners. The EV Project deployed over 12,000 alternating current Level 2 charging stations for residential and commercial use and over 100 dual-port direct current fast chargers in 17 U.S. regions. Approximately 8,300 Nissan Leafs ${ }^{\mathrm{TM}}$, Chevrolet Volts, and Smart ForTwo Electric Drive vehicles were enrolled in the project.

Project participants gave written consent for EV Project researchers to collect and analyze data from their vehicles 
and/or charging units. Data collected from the vehicles and charging infrastructure represented almost 125 million miles of driving and 4 million charging events. The data collection phase of The EV Project ran from January 1, 2011, through December 31, 2013. Idaho National Laboratory is responsible for analyzing the data and publishing summary reports, technical papers, and lessons learned on vehicle and charging unit use.

\section{Company Profile}

Idaho National Laboratory is one of DOE's 10 multi-program national laboratories. The laboratory performs work in each of DOE's strategic goal areas: energy, national security, science, and the environment. Idaho National Laboratory is the nation's leading center for nuclear energy research and development. Day-to-day management and operation of the laboratory is the responsibility of Battelle Energy Alliance.
For more information, visit avt.inl.gov/evproject.shtml and avt.inl.gov/chargepoint.shtml.

\section{References}

${ }^{1}$ “Do PEV Drivers Park Near Publicly Accessible Electric Vehicle Supply Equipment in San Diego but Not Use Them?" avt.inl.gov/evproject.shtml.

2“Categorizing Electric Vehicle Supply Equipment Venues: Describing Publicly Accessible Charging Station Locations,"

http://avt.inl.gov/pdf/EVProj/CategorizingEVSEVenuesSept 2014.pdf.

${ }^{3} \mathrm{NHTS}, 2009$, http://nhts.ornl.gov/introduction.shtml.

4"How Do The EV Project Participants Feel about Charging Their EV Away From Home?"

http://avt.inl.gov/pdf/EVProj/EVProjectParticipantsAndAway FromHomeCharging.pdf. 